justify the procedure. An example is the relief of pulmonary valve stenosis in childhood. If operation is unlikely to improve long-term prognosis, then symptoms must be very disabling to justify it, especially if the operative risk is high. The timing of surgical treatment, the results of which are continually improving, for a patient who is getting worse is one of the cardiologist's most difficult tasks at present. Disease of the aortic valve alone is the easiest to treat. Symptoms appear late, and the prognosis then is usually less than two years, often much less. Mitral valve disease is different and tends to determine the prognosis in cases of rheumatic disease of several valves. A young woman with mitral valve disease unsuitable for valvotomy may plead for relief when the medical prognosis is still 10 or 20 years or more. Would her prognosis after successful replacement by a prosthetic valve be as good ? Conversely, deterioration can be so insidious that it goes unnoticed until the optimal time for operation has passed.

In a recent preliminary report ${ }^{4}$ from six institutions in the United States the overall mortality in hospital for aortic valve replacement in 283 patients was $20 \%$, for mitral valve replacement in 216 patients was $23 \%$, for aortic and mitral valve replacement in 49 patients was $27 \%$, and for mitral and tricuspid valve replacement in 21 patients it was $48 \%$. For triple valve replacement in 16 patients the mortality was $50 \%$, and these patients still had to face their late postoperative hazards. These mortality figures are very much higher than those from other reported series; they are higher too than those which are often given both to patients and to the physicians who referred them for a surgical opinion. No one would doubt the excellence of these centres, so it is suggested that "the $24 \%$ (all over) mortality may be due primarily to the reporting of every patient." Though valve replacement still carries this grim mortality, the results daily improve and many patients are restored to enjoyable life. The same cannot yet be said of cardiac transplantation.

\section{Pregnancy Tests Over the Counter}

A woman who thinks she is pregnant usually wants to know for certain as soon as possible. Since the introduction of fast, cheap, and accurate immunological tests there has been a rapid growth of pregnancy diagnosis services advertised to the public. Last week chemists began to sell diagnostic kits over the counter, and for a price of $£ 2$ any woman can now get a result by post within 24 hours. The Council of the Pharmaceutical Society has recently proposed ${ }^{1}$ changing its code of conduct to allow pharmacists to give the results of pregnancy tests directly to their clients, and it seems likely that pharmacists will soon offer a direct service to their customers.

There is no reason to doubt the reliability or confidentiality of the services provided in Britain. The latex agglutination test is about $98 \%$ accurate when carefully performed, and no great skill is required. The test is usually positive within a week or so of the first missed period. Nevertheless, there are sound reasons for arguing that a doctor is the right person to make the diagnosis. A clinical assessment is necessary, since further investigations may be needed in any case where an abnormality is suspected. Secondly, even though all is well at the time, women who intend the preg-

${ }^{1}$ Pharmaceutical fournal, 1969, 203, 162. nancy to continue need advice on antenatal care. But probably many women who use a testing service intend to seek an abortion if the test is positive-and it is even more important that they should consult a doctor rather than an abortionist. Thirdly, women who are not pregnant but have considered it possible should probably get contraceptive advice or advice on infertility, whichever is applicable.

Why, then, do women use a postal service instead of going to their doctor ? In some cases the explanation lies in their reluctance to discuss their state with any other person at all. But too often, regrettably, the woman believes that she may get an unsympathetic hearing from her own doctor, particularly if she is not married ; while in London and other large cities many girls are not registered with a doctor at all. Doctors can do the test in their surgeries, but the reagents cost a few shillings, and no fee can be charged to an N.H.S. patient for the service. If the profession is sincere in its opposition to the lay diagnosis of pregnancy it must show greater willingness to accommodate women who don't want to "wait a few weeks" before knowing the worst-or the best; and it should urge the Health Department to make regulations to prevent doctors from being out of pocket if they help their patients in this way. But so long as some members of the public-who certainly need medical help-believe that their doctor will be unsympathetic, the laboratories offering a service by post or over the counter will do a thriving trade.

\section{Battered Babies}

Faced with a baby who shows signs of bruising, subdural haematoma, and one or more fractured bones, the average doctor is apt to cast around for some unusual syndrome, perhaps of genetic origin, to account for the condition. The thought that one or other of the parents, who may in fact have brought the baby along for treatment, could be directly responsible for its state is so repugnant to natural feeling that it does not readily come to mind. For this reason the existence of what has become known as the "battered baby" syndrome was overlooked until recent years. The first clearly identified cases in Great Britain were reported in 1963.' Reports in the U.S.A. had been appearing for some years before that, the first being in $1946 .^{2}$ The condition has since been diagnosed in other countries also.

What has not been appreciated hitherto is the high risk to subsequent children in families where the first-born was battered. This finding comes out of a study published last week. It is a report from that admirable institution the National Society for the Prevention of Cruelty to Children ${ }^{3}$ on 78 cases that came to its attention during the 12 months from 1 July 1967 . Its records showed that in families where the first child was battered there was a 13-to-1 chance that a subsequent child would be injured. Not surprisingly, many of these families have features in common.

The report states that the parents generally appeared to have long-standing emotional problems and were commonly

\footnotetext{
1 Griffiths, D. Ll., and Moynihan, F. J., British Medical fournal, 1963, 2, 1558.

affey, J., American fournal of Roentgenology, Radium Therapy, and Nuclear Medicine, 1946, 56, 163.

${ }^{3}$ Skinner, A. E., and Castle, R. L., 78 Battered Children. National Society for the Prevention of Cruelty to Children, 1 Riding House Street, London W.1 (5s. net). 1969.

British Medical Fournal, 1965, 393.

5 British Paediatric Association, British Medical fournal, 1966. 1, 601.
} 
aged between 20 and 30. Many of the fathers had criminal records and were unemployed at the time of the incident. In contrast to what might be thought, the families were usually small. The children battered were all very young, and over half of them were under a year old. That the victims of such assaults are subject to grave injury is now abundantly documented, and at least one child batterer in this country has been convicted of murder. ${ }^{4}$

The violence of the assaults and the infancy of the victims to some extent set these cases apart from other ill-treatment to which children may be subjected, though the boundaries of the syndrome cannot be regarded as clearly defined. But the need to be on the look-out for it is undoubted. For apart from the risk that a subsequent child may be assaulted there is the considerable possibility that the same child, battered once, will be battered again. The report gives some unfortunate examples of how doctors in general practice and hospitals failed to spot the nature of the case, and it also notes that "the unsatisfactory aftercare arrangements made by many hospitals despite the evidence of repeated, unexplained injury is disturbing."

The course a doctor should take when he finds himself in charge of a "battered baby" is subject to certain ethical restraints, but, as a memorandum from the British Paediatric Association $^{5}$ observed, doctors as well as being medical advisers have a duty to perform as citizens. In general the children's department of the local authority should be contacted rather than the police. What is now clear is that these cases are commoner than any ordinary person might think, and doctors have an essential role in diagnosing them correctly and taking preventive action.

\section{Human Placental Lactogen}

Several diagnostic tests for insufficiency of the placenta's function have been described. Recently a new one has appeared on the scene-human placental lactogen (H.P.L.).

First described in $1962,{ }^{1}$ human placental lactogen is a protein whose structure is similar to, but not identical with, that of human growth hormone. It has a similar molecular weight and amino-acid composition ${ }^{2}{ }^{4}$ and will react with antisera to growth hormone. ${ }^{14}$ It appears in the trophoblast very early in pregnancy ${ }^{5}$ and reaches measurable levels in maternal plasma by the sixth week. ${ }^{6-8}$ The levels then rise steadily, reaching a plateau during the third trimester. After delivery it disappears rapidly from the circulation. ${ }^{6-10}$ Human placental lactogen can be found in the mother's urine, ${ }^{11}$ in the amniotic fluid, ${ }^{11}$ and in cord blood. In the last the levels are much lower than in the maternal circulation. $^{6} 811$ It is also found in the blood of patients with trophoblastic tumours, but at much lower levels than those associated with normal pregnancy. ${ }^{6}$ Taken together, these findings suggest that H.P.L. is produced exclusively by the placenta, with no contribution from either the foetus or the mother's pituitary.

The physiological role of H.P.L. in man is uncertain. In experimental animals it has some growth-promoting activity, ${ }^{3-5}$ considerable lactogenic activity, ${ }^{1}$ and similar effects to those of growth hormone on carbohydrate and lipid metabolism. $^{312}$ In normal pregnancy production seems to be largely autonomous. The administration of either glucose or insulin has no effect on H.P.L. levels, ${ }^{6}$ in contrast to the changes found with growth hormone. ${ }^{13} 14$ In non-pregnant women it has been shown to have a diabetogenic effect, ${ }^{15}$ and it may be responsible for the exacerbation of diabetes which occurs in pregnancy.

The only method for determining the concentration of human placental lactogen in blood is by radioimmunoassay. Several techniques have been described, and the results reported by different laboratories cannot be compared directly, for there is at present no reference standard. Until this is available, each laboratory has to establish its own range of normal values. Apart from the problems of standardization the assay is relatively simple, since the hormone is a good antigen and readily iodinated. The simplicity and speed of assay may explain the recent increase of interest in the levels of this hormone as a measure of placental function.

A relationship between levels of placental lactogen in the blood and the weight of the placenta has been reported ${ }^{16}{ }^{17}$ and disputed. ${ }^{8}$ There is also disagreement about H.P.L. levels in diabetic pregnant women, for whom one group of workers has reported levels consistently higher than normal, ${ }^{17}$ while another has found no significant change. ${ }^{10}$ If there is a genuine correlation between H.P.L. levels in blood and placental mass, then it is possible that measurement of the levels might be an indicator of placental insufficiency. Two recent studies have yielded conflicting evidence on the value of this estimation in clinical practice. In a paper from Boston B. N. Saxena and colleagues, ${ }^{17}$ have reported low levels in three patients with diabetes asociated with placental insufficiency, in two patients with abruptio placentae, and in five in whom there was retarded foetal growth with no apparent cause. Four women with prolonged pregnancy showed a gradual fall in H.P.L. levels after 40 weeks of gestation. Two patients in whom there was clinical evidence of foetal distress during labour had shown decreasing levels during the last month of pregnancy. In addition, levels lower than normal were found in five women several days before spontaneous abortion. These results would suggest that the test is of considerable prognostic value in abnormal pregnancies. A rather different picture is painted by $\mathrm{N}$. A. Samaan and his colleagues from Iowa. ${ }^{18}$ Fourteen diabetic patients all showed normal values. Of three patients with rhesus immunization two had normal values and one below normal. In three patients with toxaemia, whose premature

1 Josimovich, J. B., and MacLaren, J. A., Endocrinology, 1962, 70, 209 Catt, K. J., Moffatt, B., Niall, H. D., and Preston, B. N., Biochemical fournal, 1967, 102, 270 .

3 Friesen, H., Endocrinology, 1965, 76, 369.

Kaplan, S. L., and Grumbach, M. M., Fournal of Clinical Endocrinology and Metabolism, 1964, 24, 80.

Josimovich, J. B., and Atwood, B. L., American fournal of Obstetrics and Gynecology, 1964, 88, 867.

- Samaan, N., Yen, S. C. C., Friesen, H., and Pearson, O. H., fournal of Clinical Endocrinology and Metabolism, 1966, 26, 1303.

Saxena, B. N., Refetoff, S., Emerson, K., and Selenkow, H. A., American fournal of Obstetrics and Gynecology, 1968, 101, 874.

pellacy, W. N., Carlson, K. L., and Birk, S. A., American fournal of Obstetrics and Gynecology, 1966, 96, 1164.

Kaplan, S. L., and Grumbach, M. M., Fournal of Clinical Endocrinology and Metabolism, 1965, 25, 1370.

10 Beck, P., Parker, M. L., and Daughaday, W. H., fournal of Clinical Endocrinology and Metabolism, 1965, 25, 1457.

11 Kaplan, S. L., and Grumbach, M. M., Science, 1965, 147, 751.

12 Riggi, S. J., Boshart, C. R., Bell, P. H., and Ringler, I., Endocrinology $1966,79,709$.

13 Roth, J., Glick, S. M., Yalow, R. S., and Berson, S. A., Metabolism, $1963,12,577$.

14 Hunter, W. M., Friend, J. A. R., and Strong, J. A., fournal of Endocrinology, 1966, 34, 139.

15 Samaan, N., Yen, S. C. C., Gonzalez, D., and Pearson, O. H., fournal of Clinical Endocrinology and Metabolism, 1968, 28, 485.

16 Sciarra, J. J., Sherwood, L. M., Varma, A. A., and Lundberg, W. B. American fournal of Obstetrics and Gynecology, 1968, 101, 413.

Saxena, B. N., Emerson, K., and Selenkow, H. A., New England fournal of Medicine, 1969, 281, 225.

is Samaan, N. A., Bradbury, J. T., and Goplerud, C. P., American fournal of Obstetrics and Gynecology, 1969, 104, 781. 